\title{
Chasing the fitness optimum: temporal variation in the genetic and environmental expression of life- history traits for a perennial plant
}

\author{
Mason W. Kulbaba ${ }^{1}$, Zebadiah Yoko², Jill A. Hamilton²,3,4 \\ ${ }^{1}$ Our Lady of the Lake University, Department of Biology, San Antonio, TX, \\ mkulbaba@ollusa.edu \\ ${ }^{2}$ North Dakota State University, Department of Biological Sciences, Fargo, ND, \\ zebadiah.yoko@gmail.com \\ ${ }^{3}$ Pennsylvania State University, Department of Ecosystem Science and Management, University \\ Park, PA \\ ${ }^{4}$ Author for Correspondence: Jill Hamilton, Department of Ecosystem Science and \\ Management, 323 Forest Resources Building, University Park, PA, jvh6349@psu.edu
}

2 Abstract

3 The ability of plants to track shifting fitness optima is crucial within the context of global

4 change, where increasing environmental extremes may have dramatic consequences to life

5 history, fitness, and ultimately species persistence. However, to track changing conditions relies upon the complex relationship between genetic and environmental variance, where selection may

7 favor plasticity, the evolution of genetic differences, or both depending on the spatial and

8 temporal scale of environmental heterogeneity. Over three years, we compared the genetic and environmental components of phenological and life-history variation in a common environment

10 for the spring perennial Geum triflorum. Populations were sourced from alvar habitats that

11 exhibit extreme, but predictable annual flood-desiccation cycles and prairie habitats that exhibit

12 similar, but less predictable variation in water availability. Narrow-sense heritabilities were

13 generally higher for early life history (emergence probability) relative to later life history traits

14 (total seed mass), indicating that traits associated with establishment within an environment are

15 under stronger genetic control relative to later life-history fitness expressions, where plasticity

16 may play a larger role. This pattern was particularly notable in seeds sourced from

17 environmentally extreme, but predictable alvar habitats relative to less predictable prairie seed

18 sources. Fitness landscapes based on seed source origin, largely characterized by varying water

19 availability and flower production, described selection as the degree of maladaptation to the 
20 prairie common garden environment relative to seed source environment. Plants from alvar

21 populations were consistently closer to the fitness optimum across all years. Annually, the

22 breadth of the fitness optimum expanded primarily along a moisture gradient, with inclusion of

23 more populations onto the expanding optimum. These results highlight the importance of

24 temporally and spatially varying selection for the evolution of life history, indicating plasticity

25 within perennial systems may over time become the primary mechanism to track fitness for later

26 life history events.

\section{Introduction}

29 Environmental cues essential to life history transitions may shift as a consequence of global

30 change, increasing the potential discrepancy between realized and optimal fitness (Reed et al,

31 2010; Edelaar et al, 2017). Fitness convergence requires a combination of strategies, including

32 the evolution of locally adapted genotypes that are the product of natural selection (Clausen et al,

33 1941; Hereford, 2009; Kawecki and Ebert, 2004; Leimu and Fischer, 2008) and phenotypic

34 plasticity, the ability of individual genotypes to directly alter phenotypes in response to the

35 environment (Bradshaw, 1965; Scheiner, 1993; Josephs, 2018). As environments change,

36 ensuring individuals have the capacity to maximize fitness through these strategies is crucial to

37 population persistence. However, the relative degree to which adaptive evolution or plasticity

38 evolves can vary across traits, particularly if different life history stages disproportionately

39 mediate the fitness effects of environmental heterogeneity (Roff and Mousseau, 1987). Climate

40 models predict increasing environmental heterogeneity and decreased temporal and spatial

41 predictability of environmental cues that may directly influence the ability of individuals to track

42 fitness optima via plasticity or genetic adaptation (Anderson and Gezon, 2015; Baythavong,

43 2011; Franks et al, 2013). Consequently, within the context of climate change it is essential to

44 understand the impact that spatial and temporally varying environments may have to adaptive

45 genetic differentiation and plasticity for life-history traits and long-term fitness expressions.

46 Realized phenotypes are the combined products of genetic and environmental effects and fitness

47 is an emergent property determined by the degree of similarity between individual phenotypes

48 and environmentally determined optima. With this two-fold contribution, limited variation in 
49 heritable effects or plastic responses to environmental conditions can constrain the match

50 between optimal and realized phenotypes, ultimately impacting fitness. The relative amount of

51 phenotypic variation attributed to heritable and plastic components will differ both among traits

52 (Mousseau and Roff, 1987; Price and Schluter, 1991) and environments (Hoffmann and Merila,

53 1999). For example, phenological schedules require at least some level of genetic determination

54 to initiate life-history events, but plasticity is often required to achieve maximum fitness given

55 variability inherent to natural environments. Theory suggests the proportion of phenotypic

56 variation attributed to plasticity should be greater in environments with repeated and predictable

57 cues compared to more unpredictable environments (Lande, 2009; Botero et al, 2015; Tufto,

58 2015; Leung et al, 2020). However, plasticity may be constrained when there is limited capacity

59 (Auld et al, 2010) or the maintenance and expression of plasticity is costly (DeWitt et al, 1998).

60 Greater plasticity may also evolve in traits closely linked to fitness to both maintain fitness under

61 unfavorable conditions and maximize fitness when conditions are more favorable (Sultan, 2001).

62 With expected increases in environmental variability at a global scale and decreased

63 predictability of cues under climate change (Botero et al, 2015), the likelihood of potential

64 mismatches between phenotypes and environments is increasing. This trend highlights the need

65 to refine our understanding of variation in the genetic and environmental components

66 contributing to life history evolution across spatially and temporally varying environments.

67 A major challenge to predicting responses to environmental change is the complexity of

68 interacting effects. This is particularly evident where exposure to varying degrees of micro-

69 environmental variation influence a populations' adaptive capacity (Denney et al, 2020).

70 Quantitative genetic theory predicts that trait heritability varies across environments and time

71 (Lynch and Walsh, 1998; Price and Schluter, 1991) and environmental heterogeneity can

72 contribute to the evolution of plasticity across a species' range (Baythavong, 2011; Edelaar et al,

73 2017; Kingsolver et al, 2002; Scheiner, 2013). Selection for plasticity should occur in

74 environments with predictable cues, such as those marking seasonal transitions. Such consistent

75 selection may result in reduced genetic variation for plasticity (Oostra et al, 2018). This contrasts

76 with expectations for populations sourced from unpredictable environments, where genetic

77 variation in plastic responses is expected to be maintained, enhancing trait plasticity (Ghalambor

78 et al, 2007; Chevin et al, 2010;). Given these contrasting predictions, understanding the degree to

79 which environmental heterogeneity and plasticity interact to influence phenotypic variation is 
80 essential to predicting population fitness over space and time. However, quantifying adaptive

81 evolution requires detailed estimates of the degree of constancy for quantitative genetic

82 parameters across time and environments (Young et al, 1994; Bemmels and Anderson, 2019).

83 Quantifying the relative influence of genetic and environmental variation to life history traits in

84 natural settings is difficult as the consistency of environmental cues cannot be experimentally

85 controlled. Thus, common garden experiments leveraging ecotypic variation present

86 experimental designs necessary to facilitate estimation of quantitative parameters across space

87 and time.

In the present study, we test the prediction that individuals sourced from predictably

89 heterogeneous environments will exhibit greater heritability for life history traits relative to those

90 from less predictable, but still heterogeneous environments. In addition to environment-specific

91 variation in heritability, we expect that the heritability of traits varies with ontogeny.

92 Specifically, we predict that early life history traits, such as emergence, will be under greater

93 genetic control relative to later life history stages, representing a continuum of relatively

94 heritable to plastic traits. Few studies have quantified the relative genetic and environmental

95 contributions to life history in perennial plant species due to challenges associated with

96 estimating lifetime fitness (but see Campbell, 1996; Campbell, 1997; Simons and Johnston,

97 2000). However, these data remain key to quantifying the capacity of long-lived species to

98 traverse temporal and spatially varying fitness landscapes. Finally, we evaluate individuals'

99 ability to traverse the fitness landscape following an experimental increase in distance between a

100 home and novel common garden environment. Quantifying the impact environmental

101 predictability may have to the evolution of life history, and the ability of species to compensate

102 for mismatches across life history stages will be essential to predicting the capacity for species to

103 track changing conditions and modify life-history strategies under global change.

104 We quantified temporal and spatial genetic variances for traits associated with life history and

105 fitness within the perennial forb Geum triflorum Pursch. sourced from distinct habitats with

106 contrasting predictability of environmental cues. G. triflorum is an early-season, spring perennial

107 common to midwestern prairie habitats generally characterized by cold, dry winters and hot,

108 humid summers that experience shifts in water availability both annually and seasonally that are

109 relatively unpredictable (Hamilton and Eckert, 2007; Yoko et al, 2020). This contrasts with 
110 populations of $G$. triflorum persistent on alvar habitats isolated throughout the Great Lakes

111 region of North America. Alvar habitats experience extreme, but predictable annual seasonal

112 variation in water availability from complete flooding in early spring to complete desiccation by

113 early summer (Catling and Brownell, 1995; Stark et al, 2004; Yoko et al, 2020). Specifically, we

114 ask (i) across a sequential continuum of life history events, is there variance in the heritability of

115 life history traits and expressions of fitness, and if so, are there consequences to lifetime fitness?

116 (ii) Do estimates of evolvability for life-history traits and expressions of fitness indicate the

117 potential for genotypes to become locally adapted to the common garden environment? (iii) Does

118 the heritability of phenology and life history events impede the ability of individuals to maximize

119 proximity to the optimum of the fitness landscape? Understanding how spatially and temporally

120 varying selection interact with heritable genetic and environmental components across species'

121 life history will be essential to predicting fitness under global change.

\section{Methods}

Study site and speeỉes This study focuses on Geum triflorum, commonly known as Prairie

124 Smoke, a widespread perennial forb from the Rosaceae family. Prairie Smoke is largely

125 distributed across native prairie habitat throughout the Great Plains of North America but is also

126 common on geographically disjunct alvar habitats dispersed around the Great Lakes and into

127 Manitoba, Canada. Open-pollinated maternal seed families were collected in the spring of 2015

128 from nineteen populations of G. triflorum; including eleven populations from the Great Lake

129 alvar region (GLA), two from the Manitoba alvar region (MBA), and six from the prairie (PRA)

130 region of the Midwest (Yoko et al, 2020). Within each population approximately 40 seed

131 families were collected along a $100 \mathrm{~m}$ transect (as in Hamilton and Eckert, 2007). To supplement

132 these collections, three additional bulk seed collections for prairie populations were obtained

133 from commercial seed providers (SD-PMG, MN-PMG) and the USDA-Pullman Plant Materials

134 Center (WA-BLK) (Fig. 1).

On November 7, 2015 a common garden experiment was established using open-

136 pollinated seeds at North Dakota State University (described in Yoko et al 2020). Using a

137 randomized complete block design, ten maternal seed families were planted for each population

138 across twelve blocks, including 12 individual half-sibs per maternal family. Two replicates were 
139 planted per block for bulk-collected seed, for a total of 24 seeds per bulk collection. In total,

1402348 individual seeds treated with $0.02 \%$ PPM fungicide were planted in 'cone-tainers' (158 mL,

141 Stuewe \& Sons) filled with Sungro horticulture mix (1N:45P:12K) soil in a greenhouse at North

142 Dakota State University (Table 1). The greenhouse was maintained at 15h days with

143 supplemental daylight from halide lighting at a measured flux density of $0.3383 \mathrm{mmol} \mathrm{m} 2 \mathrm{~s}-1 \mathrm{for}$

144 the duration of the experiment and temperatures fluctuating between $18.3^{\circ} \mathrm{C}$ and $23.9^{\circ} \mathrm{C}$.

145 Seedlings were watered bi-weekly and provided a slow release fertilizer mix (Osmocote 14N-

146 14P-14K) throughout the course of the experiment. In May 2016, surviving seedlings were

147 transferred to a permanent outdoor research facility at the Minnesota State University at

148 Moorhead Regional Science Center $\left(46.86913^{\circ} \mathrm{N},-96.4522^{\circ} \mathrm{W}\right)$. Individuals were planted

149 directly into the ground through cut outs in a weed barrier to limit competition. The randomized

150 block design established in the greenhouse was maintained at the permanent field site.

\section{Data Collection}

153 Phenological and life-history fitness components were evaluated within the common garden

154 from 2015 to the end of the growing season in 2018. Single season phenological observations

155 included the number of days from planting to emergence and establishment of true leaves,

156 recorded in 2015. In addition, multi-year observations were taken for number of days between

157 planting and bolting (defined as the initial elongation of the flowering stem to $\sim 7 \mathrm{~cm}$, recorded in

1582017 and 2018), days between planting and flowering (recorded annually between 2015-2018)

159 and days between planting and the initiation of infructescence development (defined as the date

160 developing woolly styles extend beyond the corolla to form a diaspore for dispersal, recorded in

1612017 and 2018).

162 To capture annual estimates of reproductive output in the common garden, cloth mesh

163 bags (Uline S-13940) were tied and labeled around each individual infructescence as the woolly

164 styles began to extend beyond the corolla. Cloth mesh bags provide the opportunity for the

165 diaspore to fully mature, while limiting potential loss of reproductive output via wind dispersal.

166 Cloth mesh bags were harvested in each August of the monitoring year. Number of reproductive

167 stems, identified as stems with infructecenses, was used to quantify the number of fruits 
168

169

170

171

172

173

174

175

176

177

178

179

\section{Statistical Analyoses}

181 To determine the narrow-sense heritability $\left(\frac{V_{A}}{V_{P}}\right)$ of life-history and phenological traits, we used generalized linear mixed models (Stroup, 2013) as implemented in the package lme4 (Bates et al, 2014) using a maternal half-sibling sampling design (Lynch and Walsh, 1998). These analyses employed the most appropriate sampling distributions and link functions for each trait (see Table 2), as determined through comparison of AIC values across models. All analyses included the effect of block and population as fixed effects, maternal family as a random effect, and the interaction between block and maternal family. Following Ahrens et al (2020) we calculated family-level heritability as:

$$
h^{2}=\left(\frac{\left(2.5 \times \operatorname{Var}_{\text {fam }}\right)}{\operatorname{Var}_{\text {fam }}+\operatorname{Var}_{\text {fam } x \text { block }}+\operatorname{Var}_{\text {error }}}\right)
$$

190 where $\operatorname{Var}_{f a m}$ is the maternal family variance, $\operatorname{Var}_{f a m} \times$ block as the variance attributed to the 191 interaction between family and block, and Var $_{\text {error }}$ as the error/residual variance. Narrow-sense 192 heritability calculations from half-sibling analyses typically multiply the numerator, $\operatorname{Var}_{f a m}$, by 1934 to account for half-sibling relatedness (Lynch and Walsh, 1998). However, G. triflorum

194 exhibits a mixed mating system that may lead to inbreeding, and the presence of inbred 
195 individuals may inflate heritability estimates. Therefore, we follow Ahrens et al (2020) and use a

196 factor 2.5 that corresponds to a coefficient of relatedness of $r=1 / 2.5$, or approximately a $30 \%$

197 selfing rate. This predicted rate of selfing rate may be high but given that half-sibling analyses

198 represents an upper limit to narrow-sense heritability, our calculation produces a conservative

199 final estimate. Finally, we estimated evolvabilities following Houle (1992) as:

$$
C V_{A}=\sqrt{\frac{\left(2.5 \times \operatorname{Var}_{f a m}\right)}{\bar{x}}}
$$

where $\bar{x}$ is the trait mean that evolvability is being calculated.

Over the course of our experiment, total fitness was estimated using aster models (Geyer et al, 2007; Shaw et al, 2008). Mean fitness was estimated for each year of the study for each of

204 the Great Lakes alvars, Manitoba alvars, and prairie regions. The graphical model for fitness

205 (Fig. 2) included individual plant assessments of emergence, survival across years, and survival to flowering modeled as Bernoulli distributions. The production of flowers, fruits, and seed mass were modeled as negative binomial distributions. The terminal fitness node of seed mass was included as the cumulative seed mass for the current and previous year, for each given year of study. We followed the recommendation of Bolker et al (2009) and Geyer et al (2013) and

210 treated block as a fixed effect. Thus, we avoid the computational issues associated with the

211 relaxation of Gaussian assumptions for random effects that relate to all generalized linear

212 models, including aster models, and are explicitly motivated by the need to model cases that do

213 not meet these specific assumptions. For each region and year combination, mean fitness was

214 represented by the median block estimate for fitness (and standard error).

215 Fitness landscapes, characterized with aster, were calculated to describe selection on

216 individuals in the common garden, while accounting for historical selection in source

217 populations through the addition of population-specific environmental summaries. To analyze

218 the expression of early phenological transitions (time to emergence in 2016) and life history trait

219 variation (number of flowers produced in each year) in the common garden environment, year-

220 specific aster models were used to calculate cumulative fitness landscapes. Time to emergence

221 and annual variation in flower production were assessed as they exhibited a relatively high 
222 proportion of heritable variation (Table 2), with increased potential to respond to selection.

223 Selection associated with the environment of origin for each population was included in the aster

224 fitness landscape models using the first principal component that differentiated population

225 climate as established in Yoko et al. (2020) based on 26 average annual climate variables

226 estimated from ClimateNA (Wang et al, 2016). We estimated selection across populations

227 planted within the common garden using the first axis of climatic variation, PC1 (43\% of total

228 variation) which previous research suggests largely follows a gradient in seasonal water

229 availability, and a second axis of climatic variation, PC2 ( $27 \%$ of total variation) that largely

230 follows a temperature gradient (Yoko et al, 2020). To allow for correlational selection in fitness

231 landscapes, aster models included the cross-products between the traits (days to emergence or

232 number of flowers) and the first principal component following Geyer and Shaw (2010). For

233 each fitness landscape, a summary of climatic variation (PC1) of origin was used as a predictor

234 variable for yearly trait observations within the common garden, including days to emergence

235 (2016) and annual number of flowers produced (2016-2018). Selection was represented by

236 distinct fitness contours associated with the year of trait observation. The steepness of the fitness

237 landscape topography, that is the magnitude of selection, is reflected by the proximity and the

238 increment of change between contour lines. We superimposed observed individual-plant

239 phenotypes on fitness landscapes to show the distribution of individuals sourced from each

240 region within the estimated selection surfaces.

\section{Results}

\section{General patterns of fitness expression and phenology}

243 Plants sourced from the two alvar habitats exhibited similar initial success in emergence relative

244 to plants sourced from prairie habitats. The proportion of seedlings that emerged from planted

245 Great Lakes alvar (972 of $1312=0.741)$ and Manitoba alvar populations $(180$ of $239=0.753)$

246 were greater than seedlings planted from Prairie populations $(298$ of $790=0.377)$. Similar

247 differentiation between alvar and prairie regions were observed for early phenological

248 expression: the mean number of days between planting to emergence (Great Lakes alvars: 10.8,

249 Manitoba alvars: 11.7, and Prairies: 14.5, all $t>3.38, \mathrm{P}<0.001$ ), planting to the production of

250 true leaves (Great Lakes alvars: 18.4, Manitoba alvars: 18.9, and Prairies: 21.5, all $t>1.99$, 
$251 \mathrm{P}<0.05$ ), and days to first flower (Great Lakes alvars: 265.2, Manitoba alvars: 271.1, and

252 Prairies: 266.1, all $t<0.85, \mathrm{P}>0.390$ ). Such regional consistency implies a common heritable

253 basis for early life history transitions in extreme, but predictable alvar habitats relative to

254 extreme, but unpredictable prairie habitats. Interestingly, early similarities between populations

255 sourced from different alvar regions disappeared with later expressions of phenology. For

256 example, the mean number of flowers produced in the second year of the study (when more

257 plants flowered to permit comparison) diverged based on habitat origin (Great Lakes alvar 8.8,

258 Manitoba alvars 4.4, Prairie 3.1, all $t<-8.87, \mathrm{P}<0.0001)$. Finally, total mean seed mass

259 (accounting for differing numbers of plants per region) differed widely across all three regions

260 (Great Lakes alvar 898.6 mg, Manitoba alvar $234.9 \mathrm{mg}$, Prairie $138.5 \mathrm{mg}$, all $t<-6.43, \mathrm{P}<$

$2610.0001)$.

Narrow-sense Heritability and Evolvability: Fitness Expressions and Phenology

263 Narrow-sense heritabilities for fitness expressions (Table 2A) were generally lower than those

264 estimated for phenological traits (Table 3A). For fitness expressions, heritability ranged from 0

265 to 0.317 , with heritability of fitness expressions from earlier life-history stages greater relative to

266 later life-history fitness expressions. Similarly, the heritability for phenological traits ranged

267 from 0 to 0.202 , with a greater contribution of heritable genetic variation to early phenological

268 transitions relative to later phenological transitions. Keeping with these estimates, evolvabilities

269 (coefficient of additive genetic variation) were also generally greater for early life-history fitness

270 expressions (Table 3A) but were generally non-existent for phenological traits (Table 3B).

271 Moreover, and in accordance with patterns of early phenological traits, the estimates of narrow-

272 sense heritability for the number of days to emergence was relatively consistent between the two

273 alvar regions (Great Lakes: 0.257, Manitoba: 0.154) when compared to populations from the

274 prairie region (0.026). Only two individuals from the Manitoba alvar and Prairie habitat types

275 produced fruit in 2016. Therefore, we did not attempt to estimate heritability or evolvabilities for

276 fruit set or seed mass in 2016 from these two regions. 
277 More generally, heritability estimates for fitness expressions and phenological traits exhibited 278 consistent variation among habitat types. Populations from both alvar regions (Great Lakes and

279 Manitoba alvars) expressed a larger proportion of heritability relative to populations from the 280 prairie region (Table 2).

\section{Mean Fitness and Selection}

282 Mean fitness, determined as annual cumulative seed mass, varied widely across regions and 283 years. Thus, we performed an analysis of regional differences across the course of each year of 284 study as the effect of region, year and their interaction where all were significant predictors for 285 fitness (all test deviance $>82.09$, all $\mathrm{P}<0.0001$ ). Fitness represented by the median block 286 estimate (and standard error) was consistently higher in plants originating from the Great Lakes 287 alvar region for all three years of study. This contrasted with plants from the Manitoba alvar and 288 Prairie regions which produced almost no seed until the second year of study (Fig. 3), precluding 289 fitness comparisons among regions in 2016. Plants from prairie populations consistently 290 exhibited reduced fitness relative to Great Lakes alvar populations, with Manitoba alvar plants 291 intermediate to the two regions. Region-specific estimates of fitness increased throughout the 292 course of our study. Whereas the rate of yearly fitness increase was much greater in Great Lake 293 compared to Manitoba alvars in the first two years of our study, the rate of annual fitness 294 increase began to converge across regions in the third year.

295 Calculation of fitness landscapes identified fitness optima for days to emergence in 2016 296 (supplementary Figure S1) and number of flowers for all three years of the study (Fig. 4A-4C) 297 with a principal component of source-population environmental variation. This principal 298 component primarily described a soil moisture gradient associated with population origin (Yoko 299 et al. 2020). Regardless of trait-PC1 combination, selection was weak in 2016 with small fitness 300 changes across fitness intervals. In subsequent years, selection on flower number and PC1

301 became stronger, and the range of optimal flower number-PC1 combination became successively 302 narrower across years (Fig. 4). Consistent with estimates of mean fitness, individuals from the 303 Great Lakes regions were consistently distributed closest to the fitness optima in each year of 304 study. 


\section{Discussion}

307 Optimizing fitness across coordinated life history events requires synchronous phenotypic 308 responses to environmental cues. This challenge is made more complex when seasonal cues are 309 unpredictable and are expected to become less predictable under global change. In this study, we 310 show that predictable seasonal cues in alvar environments have led to substantial genetic control 311 over early life history traits, such as probability and days to emergence, but plasticity in later life

312 history traits enable longer term fitness tracking. In contrast, individuals from prairie habitats,

313 which are characterized by less predictable seasonal cues, exhibit overall reduced heritability for

314 the same traits. This reduced heritability may limit the ability of a perennial species to traverse a

315 fitness landscape across generations. Thus, variance in the genetic or environmental contribution

316 to phenological and life-history trait variation may have substantial influence on fitness,

317 particularly when considering the capacity for individuals to maintain fitness across

318 environments as seasonal cues shift under global change.

\section{Heritability and Evolvability in the Common Gabden}

320 The potential for traits to respond to selection is in part dependent on the degree of standing 321 genetic variation for traits under selection. Individuals of $G$. triflorum from predictable alvar

322 habitats exhibited overall larger estimates of narrow-sense heritability in both fitness expressions

323 (Table 2) and phenology (Table 3) compared to plants from unpredictable prairie habitats. In

324 particular, the probability of emergence and total number of flowers produced in the common

325 garden, features important to fitness, were higher for alvar compared to prairie plants. Further,

326 heritability of the phenological aspect of emergence (number of days to emergence, Table 3) was

3271.5 to 2 orders of magnitude greater in plants from alvars compared to prairie habitats.

328 Importantly, this has implications for estimates of evolvability as the timing of emergence for

329 plants from alvar habitats were twice that of plants from prairie habitats. Therefore, the

330 probability and timing of emergence is expected to be approximately twice as responsive to

331 selection in plants from alvars compared to prairies. Interestingly, the probability of emergence,

332 that exhibits the highest degree of evolvability, was comparable across regions (Table 2), 
333 suggesting that although the heritability for emergence in prairie environments is reduced, the

334 potential response to selection is similar across habitat of origin.

336 The timing of seedling emergence is an ecologically important aspect of phenology and closely

337 associated with fitness. When a seedling emerges determines the future environment experienced

338 during growth, reproduction, and seed dispersal (Evans and Cabin, 1995), and has thus been

339 interpreted as a form of niche construction (Donohue, 2005). Therefore, local adaptation should

340 include a strong heritable basis for the timing of emergence. In our study, estimates of

341 heritability and evolvability were greater in plants from alvar compared to prairie environments.

342 With predictable seasonal extremes of flooding and drought in alvars (Reschke et al, 1999),

343 individuals have little time to complete reproductive cycles. Therefore, a strong heritable basis

344 for the timing of emergence should be prevalent in alvar environments to maximize the amount

345 of time for reproductive effort before the onset of late-season dormancy. In contrast, prairie

346 environments lack this consistent signal of environmental coordination and therefore employ a

347 more attenuated emergence schedule. Greater plasticity in timing of emergence is reflected in

348 overall lower estimates of heritability in plants from PRA populations (Table 3).

349 An alternative explanation for the difference in the magnitude of heritability between GLA and

350 PRA plants could be attributed to variation in the demography of GLA populations. These

351 populations are generally large and exhibit increased density within similar spatial extents

352 relative to prairie populations (Hamilton and Eckert, 2007). Further, alvar habitats typically

353 experience reduced competition due to the unique environmental features that support the

354 persistence of select flora on these habitats (Partel et al, 1998). This contrasts with prairie

355 habitats where PRA populations may also be fragmented, but forbs often experience increased

356 competition with native and invasive grasses (Dickson and Busby, 2009).

358 Predictably varying environments present populations with a consistent pattern of selection, 359 resulting in an evolutionary response provided sufficient standing genetic variation exists.

360 However, consistent and predictable selection need not necessarily erode additive genetic 
361 variation for traits as traditionally conjectured for traits presumed to be closely associated with

362 fitness (Roff and Mousseau, 1987; McFarlane et al, 2014). Provided that sufficient annual

363 variation in the predictable environmental cue exists, optimal responses to this cue will vary

364 across years. Therefore, fluctuation in the direction and magnitude of selection may maintain

365 appreciable additive genetic variation (Bell, 2010). Such a pattern was observed in the timing of

366 emergence and flowering regardless of habitat of origin (Table 3).

367 Given the importance of the timing of emergence to subsequent life-history events, a strong

368 genetic basis could provide a consistent start point for life cycles. However, greater

369 environmental variation associated with later life history events could cumulatively impact the

370 evolutionary trajectory of phenotypic traits. Indeed, later life-history expressions have been

371 predicted to exhibit relatively reduced estimates of heritability (Price and Schluter, 1991).

372 Therefore, the degree of plasticity for post-emergence life-history events would be much greater

373 than during early life-cycle events. Estimates of heritability and evolvability for the timing of

374 emergence were always greater regardless of habitat of origin. Heritability for the timing of

375 flowering was reduced, but still appreciable compared to the remaining life history events. This

376 pattern matches our predictions of a greater importance of heritable variation in early life history

377 events with a minor role for plasticity. During later events, environmental variance is greatest

378 and therefore plasticity will have a relatively larger effect on phenotypic variance. This pattern

379 implies some continuum of the relative effects of heritable and environmental variance on

380 phenotypic variation. Such a continuum implies an intermediate life-history expression that has

381 an approximately equal proportion of heritable and plastic determinism. Given the intermediate

382 estimates of heritability for the timing of flowering (across years; Table 3), this life-history event

383 may represent such an intermediate. Indeed, this phenological signpost has been shown to exhibit

384 similar magnitudes of narrow-sense heritability in similar systems (Burgess et al, 2007; Geber

385 and Griffen, 2003; Goncalves-Vidigal et al, 2008; Mitchell and Shaw, 1993; O’Neil, 1997;

386 Wheelwright, 1985), and other studies confirming adaptive plasticity in the timing of flowering

387 (Donohue et al, 2000; Jimenez-Ambriz et al, 2007). Plasticity in flowering time seems to be

388 more common than not (Levin, 2009). For example, Ensing and Eckert (2019) report a gradient

389 of plasticity that resulted in the timing of flowering in Rhinanthus minor transplanted along a

390 range of altitudes that plastically shifted flowering time to match those of new conspecifics. This 
391 midpoint life history event may represent the transition when environmental variation begins to

392 exceed heritable variation in determining phenotypic variation, and ultimately population fitness.

394 Estimates of heritability can vary across years for the same trait in the same locality. However, if 395 heritability estimates are constant across environments some ability to predict phenotypes as a 396 response to selection exists. For example, Young et al (1994) determined consistent heritability 397 of floral traits in Raphanus sativus in three different environments, indicating the absence of a 398 genotype-by-environment interaction. Therefore, the expectation is that selection acting on these 399 traits would result in environment-specific changes in phenotypes. In contrast, our results suggest 400 that in general, heritability for expressions of fitness (flower number, fruit number, and seed 401 mass) of plants from alvar habitats decreased over time, supporting the prediction from Price and 402 Schluter (1991) that the cumulative exposure to environmental variability limits the estimate of 403 narrow-sense heritability. The same traits in plants from prairie environments exhibited very 404 little variation across years, and overall negligible estimates of heritability. Similarly, heritability 405 estimates for fitness expressions were overall smaller than those for phenology traits, regardless 406 of habitat origin.

407 The expression of additive genetic variation is dependent on local environmental conditions 408 (Hoffmann and Merila, 1999; Sheth et al, 2018) and may change under unfavorable or stressful 409 conditions (Emery and Ackerly, 2014; Schlichting, 2008). Therefore, the potential rate of the 410 response to selection will depend on the environment-specific expression of additive genetic 411 variation. For example, Torres-Martinez et al (2019) found greater short-term potential for 412 adaptation during stressful drought (La Niña) years compared to more favorable wet (El Niño) 413 years in an experimental precipitation gradient in Lasthenia fremontii. The temporal availability 414 of water in alvar habitats likely imposes severe drought stress that accompanies periods of 415 drought (Lundholm and Larson, 2003; Rosén, 1995; Schaefer and Larson, 1997). Individuals in 416 our study from alvar communities likely experienced drought stress during later life history 417 stages, predicting higher expressions of additive genetic variance and narrow-sense heritability 418 (but see Blows and Sokolowski, 1995; Charmantier and Garant, 2005). This may seem in 419 conflict with the above discussion of later life-history events exhibiting smaller estimates of 
420 heritability, as found in our study. However, enhanced expression of additive genetic variance

421 does not necessarily equate to larger estimates of heritability, but rather, depends on the

422 proportion of environmental variation associated with traits. Therefore, the cumulatively larger

423 environmental variance associated with the later life-history events occurring throughout times

424 of drought could reduce heritabilities regardless of enhanced expression of additive genetic

425 variance. Our estimates of low heritability and evolvability of life-history events during these

426 periods of stress suggest that environmental variance could hamper an adaptive response to

427 selection (Falconer and Mackay, 1996; Levin, 1998, but see Ghalambor et al 2007).

\section{Mean Lifetime Fitness and Fitness Landscapes}

430 Mean fitness, as determined through aster models, relates directly to per capita rates of

431 population increase, and therefore population sustainability and growth. Interestingly, plants

432 from GLA populations consistently exhibited the highest fitness estimates in the common garden

433 environment across all three years (Fig. 3). This was unexpected as alvar habitats differ

434 markedly, especially in terms of water availability, from prairie habitats. Even plants sourced

435 from prairie environments in close proximity to the common garden did not perform nearly as

436 well as plants from either MBA or GLA populations. The large discrepancy in fitness may be

437 attributed to low germination success in prairie plants (37.7\%) compared to plants from Great

438 Lakes (74.1\%) and Manitoba (75.3\%) alvars. Overall, fitness was low in the first year of our

439 study, as plants became established in the common garden and with relatively fewer plants

440 flowering compared to subsequent years. In the remaining two years of study, as fitness

441 increased across all regions of origin, the difference in fitness among regions increased while

442 maintaining the same pattern of fitness expression (Fig. 3). Therefore, the pattern of plants from

443 GLA populations exhibiting higher fitness in the common garden was not a short-term artifact of

444 establishment.

445 The expression of fitness, much like the expression of additive genetic effects, is dependent on

446 the environment. When genotypes are moved from their home range to a novel environment,

447 fitness may decrease as a sign of local adaptation (Garrido et al, 2012; Hereford, 2009), increase

448 (e.g., Sheth et al. 2018), or remain constant (Galloway and Fenster, 2000). In our study, the 
movement of genotypes that evolved under GLA environments to the prairie environment of the

450 common garden resulted in an increase in fitness. Yoko et al. (2020) detected trait enhancements

451 associated with water-use efficiency, among others, in plants from alvars compared to prairie

452 environments. Plants originating from alvars would experience greater water availability in the

453 prairie environment of the common garden, where thick rich soils mitigate unpredictable

454 fluctuations in water availability ( Risser et al, 1981;Anderson, 2006). Therefore, enhanced

455 water-use efficiency of alvar plants could provide a physiological advantage over prairie plants

456 that would not historically experience predictable seasonal drought conditions. Finally,

457 ecological differences rather than physical distances are likely more important in determining

458 fitness in our common garden. However, to fully evaluate the preadaptation of alvar plants would

459 require a reciprocal transplant experiment with both alvar and prairie populations.

Fitness Landscapes

461 Annual changes in mean fitness across source habitats corresponded with changes in the

462 magnitude of selection as determined through fitness landscapes. Total flower number is

463 commonly found to be under selection (Harder and Johnson, 2009) and therefore closely linked

464 to fitness. We found moderate selection on the total number of flowers produced along an axis of

465 environmental variation (moisture gradient) for source populations. The magnitude of selection

466 along the axis of environmental variation represents the difference in environment between

467 source populations and the common garden, describing the discrepancy between fitness optima

468 across source populations and the novel common garden environment. Thus, the change in

469 selection along the environmental gradients represents the degree of maladaptation following

470 introduction to a novel environment.

471 The location of fitness optima consistently tracked mean fitness for each source population

472 habitat type (Fig. 3, Fig. 4). Fitness across all source populations were modest in the first year of

473 study with few individuals reproducing. Consequently, the fitness landscape (Fig. 4A) was

474 relatively flat with a wide but shallow plateau surrounding the optima. In the two remaining

475 years of the study, the topography of the landscapes became steeper indicating stronger selection,

476 with successively more plants occupying the region around the fitness optima. Regardless of

477 year, plants from the Great Lakes alvars were consistently closer to the fitness optima. Alvar 
478 habitats experience consistent extremes in water availability with annual late-season desiccation

479 (Catling and Brownell, 1995). Lack of water availability favors selection for plants with reduced

480 water potential and enhanced water-use efficiency (Craine and Dybzinski, 2013). Thus, plants

481 originating from predictably water-stressed environments like alvars, could express release from

482 water-use constraints, effectively enhancing fitness in response to increased water availability

483 within the prairie common garden environment. In contrast, plants from prairie populations did

484 not experience such a drastic change in water availability. Therefore, and unexpectedly, the

485 degree of environmental maladaptation in the common garden environment was greater for

486 plants from prairie populations than for plants from alvar populations.

487 Over successive years, the breadth of the fitness optimum increased along the axis of

488 environmental variation but was relatively constrained along the axis of total flower production.

489 Given the relatively high heritability in flower number across all three years of study (Table 2),

490 the limited plasticity in flower number may be responsible for this constraint. In contrast,

491 enhanced plasticity for water use traits has been associated with improved survival and seed

492 production (Nicotra and Davidson, 2010). Therefore, the more predictable seasonal changes in

493 water availability in alvar habitats may promote enhanced plasticity in water use traits, whereas

494 flower number would remain relatively constant within a habitat type. However, across habitat

495 types, total flower production was greater in plants from alvars with predictable changes in water

496 availability compared to prairie habitats. Regardless of habitat origin, the degree of plasticity

497 associated with flower number was restricted compared with that of water availability.

498 Therefore, the restricted plastic response of flower production would impose a strong limitation

499 to fitness and local adaption in the common garden environment.

500 Total fitness is the cumulative expression of an individual's fitness components across its life

501 cycle, from emergence and survival to the total number of offspring produced. Individual fitness

502 expressions are the results of genetic and environmental effects, as well as their interaction. We

503 observed that the independent and interactive effects of these components vary continuously

504 across life histories. The relative degree of genetic and environmental contribution to trait

505 variation provides a new perspective to the dynamics of life-history traits. We found a shift from

506 genetic to greater environmental effects across successive years, allowing plants furthest from

507 the fitness optimum to traverse the fitness landscape and increase proximity to the fitness 
optimum. Plants sourced from predictable alvar environments started closest to, and maintained proximity, to the fitness optimum across years. Whereas plants from unpredictable prairie environments were initially furthest from the fitness optimum, these plants were able to quickly

511 approach the fitness optimum. Overall, these results highlight the importance of environmental

512 variation in facilitating movement across the fitness landscape, and genetic variation in

513 maximizing fitness near the optimum.

\section{Acknowledgements}

The authors thank Jon Sweetman, Chad Stratilo, Mary Vetter, Rebekah Neufeld, Tyler Stadel, Steve Travers, and the Nature Conservancy of Canada for help with initial field sampling for seeds. In addition, we thank Stephen Johnson, Nick Hugo, Alexis Pearson, Zoe Portlas, Naomi Hegwood, Storm Nies, and Kate Volk for assistance in the field. Thanks also to Tony Bormann (MSUM Science Center) for logistical support and Ruth Shaw, Frank Shaw, and Charles Geyer for guidance with aster modeling.

This work was supported by a new faculty award from the office of the North Dakota Experimental Program to Stimulate Competitive Research (ND-EPSCoR NSF-IIA-1355466) and funding from the NDSU Environmental and Conservation Sciences Graduate Program to J.A.H.

\section{Author Contributions}

JH led the initial field collections and designed the study. JH and ZY participated in field work and data collection, MWK performed the main analyses. MWK led the manuscript writing with considerable input from $\mathrm{JH}$ and $\mathrm{ZY}$.

\section{Data Accessibility}

\section{Figure Captions}

515 Figure 1. Map indicating location of common garden (star) and Great Lakes Alvar (GLA - open

516 circles), Manitoba Alvars (MBA - light grey circles), and Prairie (PRA - dark grey circles)

517 source populations of Geum triflorum.

518 Figure 2. Graphical model used to estimate lifetime fitness for each plant in the common garden.

519 Each node represents a fitness component and therefore response variable, and arrows represent 520 conditional distributions. Probability of germination, flowering, and survival ( 0 or 1 ; Bernoulli 521 distribution), and total number of flowers, total number of fruits and seed mass (negative 522 binomial). Seed mass for each year was calculated as the sum of seed mass for the current year 523 and all previous years of the experiment.

524 Figure 3. Estimated mean fitness and standard errors for plants from Great Lakes Alvars (open 525 circles), Manitoba Alvars (open squares), and Prairie (open triangles) source populations across 526 three successive years. 
527 Figure 4. Fitness landscapes for the total number of flowers produces and a principal component 528 describing a moisture gradient based on climate of origin for seed source populations from Yoko 529 et al. (2020) over three consecutive years in the common garden (panel A-C). Points denote 530 observed numbers of flowers, and line contours indicate fitness contours determined with aster 531 models following Geyer and Shaw (2008). Great Lakes Alvars (open circles), Manitoba Alvars 532 (light grey circles), and Prairie (dark grey circles) source populations and identified fitness 533 optimum (red triangle) are indicated.

535 Supplemental Figure A. Fitness landscapes for the number of days to emergence from planting 536 and a principal component describing a moisture gradient in source populations from Yoko et al. 537 (2020) for the first year of study (2016). Points denote observed numbers of days to emergence 538 and line contours indicate fitness contours determined with aster models following Geyer and 539 Shaw (2008). Great Lakes Alvars (open circles), Manitoba Alvars (light grey circles), and Prairie 540 (dark grey circles) source populations and identified fitness optimum (red triangle) are indicated. 


\section{References}

542

543

544

545

546

547

548

549

550

551

552

553

554

555

556

557

558

559

560

561

562

563

564

565

566

567

568

569

570

571

572

573

574

575

576

577
Ahrens CW, Andrew ME, Mazanec RA, Ruthrof KX, Challis A, Hardy G et al (2020). Plant functional traits differ in adaptability and are predicted to be differentially affected by climate change. Ecology and Evolution 10: 232-248.

Anderson JT, Gezon ZJ (2015). Plasticity in functional traits in the context of climate change: a case study of the subalpine forb Boechera stricta (Brassicaceae). Global Change Biology 21: 1689-1703.

Anderson RC (2006). Evolution and origin of the Central Grassland of North America: climate, fire, and mammalian grazers. The Journal of the Torrey Botanical Society 133: 626-647.

Auld JR, Agrawal AA, Relyea RA (2010). Re-evaluating the costs and limits of adaptive phenotypic plasticity. Proceedings of the Royal Society B: Biological Sciences 277: 503-511.

Bates DM, Maechler M, Bolker B, Walker S (2014). lme4: linear mised-effects model using Eigen and S4. R package version 11-6.

Baythavong BS (2011). Linking the spatial scale of environmental variation and the evolution of phenotypic plasticity: selection favors adaptive plasticity in fine-grained environments. The American Naturalist 178: 75-87.

Bell G (2010). Fluctuating selection: the perpetual renewal of adaptation in variable environments. Philosophical Transactions of the Royal Society B: Biological Sciences 365: 8797.

Bemmels JB, Anderson JT (2019). Climate change shifts natural selection and the adaptive potential of the perennial forb Boechera stricta in the Rocky Mountains. Evolution 73: 22472262.

Blows MW, Sokolowski MB (1995). The expression of additive and nonadditive genetic variation under stress. Genetics 140: 1149-1159.

Bolker B, Brooks M, Clark CJ, Geange SW, Poulsen JR, Stevens MHH et al (2009). Generalized linear mixed models: a practical guide for ecology and evolution. Trends in Ecology \& Evolution 24: $127-135$. 
Botero CA, Weissing FJ, Wright JW, Rubenstein DR (2015). Evolutionary tipping points in the capacity to adapt to environmental change. Proceedings of the National Academy of Science USA 112: $184-189$.

Bradshaw AD (1965). Evolutionary significance of phenotypic plasticity. Advances in Genetics 13: $115-155$.

Burgess KS, Etterson JR, Galloway LF (2007). Artificial selection shifts flowering phenology and other correlated traist in an autotetraploid herb. Heredity 99: 641-648.

Campbell DR (1996). Evolution of floral traits in a hermaphroditic plant: field measurements of heritabilities and genetic correlations. Evolution 50(4): 1442-1453.

Campbell DR (1997). Genetic and environmental variation in life-history traits of a monocarpic perennial: a decade-long field experiment. Evolution 51(2): 373-382.

Catling PM, Brownell VR (1995). A review of the alvars of the great lakes region: distribution, floristic composition, biogeography and protection. Canadian Field Naturalist 109: 143-171.

Charmantier A, Garant D (2005). Environmental quality and evolutionary potential: lessons from wild populations. Proceedings of the Royal Society B: Biological Sciences 272: 1415-1425.

Chevin L, Lande R, Mace GM (2010). Adaptation, plasticity, and extinction in a changing environment: towards a predictive theory. PLoS Biology 8(4): e1000357.

Clausen J, Keck D, Hiesey WM (1941). Regional differentiation in plant species. The American Naturalist 75: 231-250.

Craine JM, Dybzinski R (2013). Mechanisms of plant competition for nutrients, water and light. Functional Ecology 27: 833-840.

Denney DA, Inam Jameel M, Bemmels JB, Rochford ME, Anderson JT (2020). Small spaces, big impacts: contributions of micro-environmental variation to population persistence under climate change. AoB Plants 12. 
614 DeWitt TJ, Sih A, Wilson DS (1998). Costs and limits of phenotypic plasticity. Trends in

615 Ecology \& Evolution 13: 77-81.

616

617

618

619

620

621

622

623

624

625

626

627

628

629

630

631

632

633

634

635

636

637

638

639

640

Dickson TL, Busby WH (2009). Forb species establishment increases with decreased grass seeding density and with increased forb seeding density in a Northeast Kansas, U.S.A., experimental prairie restoration. Restoration Ecology 17: 597-605.

Donohue K (2005). Niche construction through phenological plasticity: life history dynamics and ecological consequences. New Phytologist 166: 83-92.

Donohue K, Messiqua D, Pyle EH, Heschel MS, Schmitt J (2000). Evidence of adaptive divergence in plasticity: desnity- and site-dependent selection on shade avoidance responses in Impatiens capensis. Evolution 54: 1956-1968.

Edelaar P, Jovani R, Gomez-Mestre I (2017). Should I change of should I go? Phenotypic plasticity and matching habitat choice in the adaptation to environmental heterogeneity. The American Naturalist 190: 506-520.

Emery NC, Ackerly DD (2014). Ecological release exposes genetically based niche variation. Ecology Letters 17: 1149-1157.

Ensing DJ, Eckert CG (2019). Interannual variation in season length is linked to strong cogradient plasticity of phenology in a montane annual plant. New Phytologist 224: 1184-1200.

Evans AS, Cabin RJ (1995). Can dormancy affect teh evolution of post-germination traits? The case of Lesquerella fendler. Ecology(72).

Falconer DS, Mackay FC (1996). Introduction to quantitative genetics.

Franks SJ, Weber JJ, Aitken SN (2013). Evolutionary and plastic responses to climate change in terrestrial plant populations. Evolutionary Applications: 123-139.

Galloway LF, Fenster CB (2000). Population differentiation in an annual legume: local adaptation. Evolution 54: 1173-1181.

Garrido JL, Rey PJ, Herrera CM, Ramirez JM (2012). Negative evidence of local adaptation to the establishment conditions in a perennial herb. Plant Ecology 213: 1555-1569. 
652 Geber MA, Griffen LR (2003). Inheritance and natural selection on functional traits.

International Journal of Plant Sciences 164: S21-S42.

654

655

656

657

658

659

660

661

662

663

664

665

666

667

668

669

670

671

672

673

674

675

676

677

678

679

680

681

682

683

684

685

Geyer CJ, Ridley CE, Latta RG, Etterson JR, Shaw RG (2013). Local adaptation and genetic effects on fitness: calculations for exponential family models with random effects. The Annals of Applied Statistics 7: 1778-1795.

Geyer CJ, Shaw RG. (2010). School of Statistics UoM (ed.).

Geyer CJ, Wagenius S, Shaw RG (2007). Aster models for life history analysis. Biometrika 94: 415-426.

Ghalambor CK, McKay JK, Carroll SP, Reznick DN (2007). Adaptive versus non-adaptive phenotypic plasticity and the potential for contemporary adaptation in new environments. Functional Ecology 21: 394-407.

Goncalves-Vidigal MC, Mora F, Bignotto TS, Munhoz REF, de Souza LD (2008). Heritability of quantitative traits in segregating common bean families using a Bayesian approach. Euphytica 164: 551-560.

Hamilton JA, Eckert CG (2007). Population genetic consequences of geographic disjunction: a prairie plant isolated on Great Lakes alvars. Molecular Ecology 16(8): 1649-1660.

Harder LD, Johnson SD (2009). Darwin's beautiful contrivances: evolutionary and functional evidence for floral adaptation. New Phytologist 183: 530-545.

Hereford J (2009). A quantitative survey of local adaptation and fitness trade-offs. The American Naturalist 173(5): 579-588.

Hoffmann AA, Merila J (1999). Heritable variation and evolution under favourable and unfavourable conditions. Trends in Ecology \& Evolution 14: 96-101.

Houle D (1992). Comparing evolvability and variability of quantitative traits. Genetics 130: 195 204. 
Jimenez-Ambriz G, Petit C, Bourrie I, Subois S, Olivieri I, Ronce O (2007). Life history variation in the heavy metal tolerant plant Thlaspi caerulescens growing in a network of contaminated and noncontaminated sites in southern France: role of gene flow, selection and phenotypic plasticity. New Phytologist 173: 199-215.

691

692

693

694

695

696

697

698

699

700

701

702

703

704

705

706

707

708

709

710

711

712

713

714

715

716

717

718

719

720

721

722

723

Josephs EB (2018). Determining the evolutionary forces shaping G x E. New Phytologist.

Kawecki TJ, Ebert D (2004). Conceptual issues in local adaptation. Ecology Letters 7: 12251241.

Kingsolver JG, Pfennig DW, Servedio MR (2002). Migration, local adaptation and the evolution of plasticity. Trends in Ecology \& Evolution 17: 540-541.

Lande R (2009). Adaptation to an extraordinary environment by evolution of phenotypic plasticity and genetic assimilation. Journal of Evolutionary Biology 22: 1435-1446.

Leimu R, Fischer M (2008). A meta-analysis of local adaptation in plants. PLoS One 3(12): e4010.

Leung C, Rescan M, Grulois D, Chevin L (2020). Reduced phenotypic plasticity evolves in less predictable environments. BioRxiv.

Levin DA (1998). Local differentiation and the breeding structue of plant populations. Springer: Dordrecht.

Levin DA (2009). Flowering-time plasticity facilitates niche shifts in adjacent populations. New Phytologist 183: 661-666.

Lundholm JT, Larson DW (2003). Relationships between spatial environmental heterogeneity and plant species diversity on a limestone pavement. Ecography 26: 715-722.

Lynch M, Walsh B (1998). Genetics and analysis of quantitative traits. Sinauer: Sunderland, MA.

McFarlane SE, Gorrell JC, Coltman DW, Humphries MM, Boutin S, McAdam AG (2014). Very low levels of direct additive genetic variance in fitness and fitness components in a red squirrel population. Ecology and Evolution 4: 1729-1738. 
Mitchell RJ, Shaw RG (1993). Heritability of floral traits for the perennial wild flower Penstemon centranthifolius (Scrophulariaceae): clones and crosses. Heredity 71: 185-192.

Mousseau TA, Roff DA (1987). Natural selection and the heritability of fitness components. Heredity 59: 181-197.

Nicotra AB, Davidson AM (2010). Adaptive plasticity in water use traits. Functional Plant Biology 37: 117-127.

O’Neil P (1997). Natural selection on genetically correlated phenological characters in Lythrum salicaria L. (Lythraceae). Evolution 51: 267-274.

Oostra V, Saastamoinen M, Zwaan BJ, Wheat CW (2018). Strong phenotypic plasticity limits potential for evolutionary responses to climate change. Nature Communications 9: 1005.

Partel M, Kalamees R, Zobel M, Rosen E (1998). Restoration of species-rich limestone grassland communities from overgrown land: the importance of propagule availability. Ecological Engineering 10.

Price T, Schluter D (1991). On the low heritability of life-history traits. Evolution 45: 853-861.

Reed TE, Waples RE, Schindler DE, Hard JJ, Kinnison MT (2010). Phenotypic plasticity and population viability: the importance of environmental predictability. Proceedings of the Royal Society B: Biological Sciences 277: 3391-3400.

Reschke C, Reid R, Jones J, Feeney T, Potter H. (1999). Great Lakes Program. Conservancy TN (ed.): Chicago, IL.

Risser PG, Birney EC, Blocker HD. (1981).

Roff DA, Mousseau TA (1987). Quantitative genetics and fitness: lessons from Drosophila. Heredity 58: 103-118.

Rosén E (1995). Periodic droughts and long-term dynamics of alvar grassland vegetation on Oland, Sweden. Folia Geobotanica 30: 131-140. 
Schaefer CA, Larson DW (1997). Vegetation, environmental characteristics and ideas on the maintenance of alvars on the Bruce Peninsula, Canada. Journal of Vegetation Science 8: 797810.

Scheiner SM (1993). Genetics and evolution of phenotypic plasticity. Annual Review of Ecology and Systematics 24: 35-68.

Schlichting CD (2008). Hidden reaction norms, cryptic genetic variation, and evolvability.

Sheth SN, Kulbaba MW, Pain RE, Shaw RG (2018). Expression of additive genetic variance for

Simons AM, Johnston MO (2000). Variation in seed traits of Lobelia inflata (Campanulaceae): sources and fitness consequences. American Journal of Botany 87: 124-132.

782

783

784

785

Stark KE, Lundholm JR, Larson DW (2004). Arrested development of soil on alvars of Ontario, Canada: implications for conservation and restoration. Natural Areas Journal 24: 95-100.

Stroup WW (2013). Generalized linear mixed models: modern concepts, methods and applications. CRC Press: Boca Raton, FL.

Sultan S (2001). Phenotypic plasticity for fitness components in Polygonum species of contrasting ecological breadth. Ecology 82: 328-343.

Torres-Martinez L, McCarten N, Emery NC (2019). The adaptive potential of plant populations in response to extreme climate events. Ecology Letters(22): 866-874.

Tufto J (2015). Genetic evolutoni, plasticity and bet-hedging as adaptive responses to temporally autocorrelated fluctuating selection: a quantitative genetic model. Evolution 69: 2034-2049. 
Wang T, Hamann A, Spittlehouse D, Carroll C (2016). Locally downscaled and spatially

$800 \mathrm{e} 0156720$.

801

802

Wheelwright NT (1985). Competition for dispersers, and the timing of flowering and fruiting in 803 a guild of tropical trees. Oikos 44: 465-477.

804

805 Yoko Z, Volk K, Dochtermann NA, Hamilton JA (2020). The importance of quantitative trait 806 differentiation in restoration: landscape heterogeneity and functional traits inform seed transfer 807 guidelines. AoB Plants.

808

809 Young HJ, Stanton ML, Ellstrand NC, Clegg JM (1994). Temporal and spatial variation in 810 heritability and genetic correlations among floral traits in Raphanus sativus, wild radish.

811 Heredity 73: 298-308. 
Table 1 - Source populations of G. triflorum collected in 2015 spanning three distinct eco-regions (Great Lake alvars (GLA), Manitoba alvars (MBA), and Prairies (PRA)), along with latitude, longitude, and elevation $(\mathrm{m})$ of population collection sites. Distance from common garden $(\mathrm{km})$ notes the greater circle distance calculated between the population origin and the common garden experiment established at Minnesota State University at Moorhead Regional Science Center, Moorhead, Minnesota, United States.

\begin{tabular}{|c|c|c|c|c|c|}
\hline Population ID & Region & Latitude & Longitude & $\begin{array}{l}\text { Elevation } \\
(\mathrm{m})\end{array}$ & $\begin{array}{l}\text { Distance from } \\
\text { Common } \\
\text { Garden } \\
\text { Experiment } \\
(\mathrm{km})\end{array}$ \\
\hline CAR-NBA & GLA & 44.69 & -79.05 & 268 & 1368 \\
\hline CAR-PSR & GLA & 44.65 & -79.09 & 250 & 1366 \\
\hline MAN-FOX & GLA & 45.90 & -82.58 & 186 & 1068 \\
\hline MAN-KIP & GLA & 45.87 & -82.54 & 183 & 1072 \\
\hline MAN-LCI & GLA & 45.99 & -81.89 & 182 & 1118 \\
\hline MAN-MIS & GLA & 45.81 & -82.76 & 193 & 1056 \\
\hline MI-DRI & GLA & 46.09 & -83.69 & 188 & 980 \\
\hline NAP-ASS & GLA & 44.27 & -76.71 & 126 & 1559 \\
\hline NAP-CE & GLA & 44.33 & -76.79 & 166 & 1551 \\
\hline NAP-SCH & GLA & 44.34 & -76.89 & 154 & 1543 \\
\hline WNY-CB & GLA & 44.10 & -76.08 & 93 & 1613 \\
\hline MB-CRN & MBA & 51.07 & -97.46 & 231 & 473 \\
\hline MB-MR & MBA & 51.18 & -97.63 & 231 & 487 \\
\hline$A B-H S C$ & PRA & 49.64 & -110.33 & 721 & 1071 \\
\hline$A B-L L$ & PRA & 49.54 & 114.25 & 929 & 1348 \\
\hline$A B-R L$ & PRA & 49.67 & -110.11 & 721 & 1056 \\
\hline$A B-R O$ & PRA & 49.67 & 110.15 & 721 & 1059 \\
\hline MN-PMG & PRA & 47.77 & -96.61 & 267 & 101 \\
\hline ND-BSP & PRA & 46.86 & -96.47 & 274 & 2 \\
\hline SD-MUD & PRA & 44.76 & -96.59 & 531 & 234 \\
\hline SD-PMG & PRA & 45.22 & -96.63 & 351 & 184 \\
\hline WA-BLK & PRA & 46.69 & -116.97 & 786 & 1558 \\
\hline $\begin{array}{l}\text { CommonGarden } \\
\text { Experiment }\end{array}$ & PRA & 46.87 & -96.45 & 259 & - \\
\hline
\end{tabular}


Table 2. (A) Narrow-sense heritability and standard error and (B) evolvability (coefficient of additive genetic variation) of Geum triflorum fitness expressions grown in a common garden environment.

\begin{tabular}{|c|c|c|c|c|c|c|c|c|c|c|c|}
\hline Region & Emergence & $\begin{array}{c}2016 \\
\text { Flower } \\
\text { Number } \\
\end{array}$ & $\begin{array}{c}2017 \\
\text { Flower } \\
\text { Number } \\
\end{array}$ & $\begin{array}{c}2018 \\
\text { Flower } \\
\text { Number } \\
\end{array}$ & $\begin{array}{c}2016 \\
\text { Fruit } \\
\text { Number } \\
\end{array}$ & $\begin{array}{c}2017 \\
\text { Fruit } \\
\text { Number } \\
\end{array}$ & $\begin{array}{c}2018 \\
\text { Fruit } \\
\text { Number } \\
\end{array}$ & $\begin{array}{c}\text { Seed } \\
\text { Mass } \\
2016 \\
\end{array}$ & $\begin{array}{c}\text { Seed } \\
\text { Mass } \\
2017 \\
\end{array}$ & $\begin{array}{c}\text { Seed } \\
\text { Mass } \\
2018 \\
\end{array}$ & $\begin{array}{c}\text { Cumulative } \\
\text { Seed Mass } \\
\text { to } 2017 \\
\end{array}$ \\
\hline $\begin{array}{l}\text { Great Lakes } \\
\text { Alvar }\end{array}$ & $\begin{array}{l}0.644 \\
-0.02\end{array}$ & $\begin{array}{c}0.196 \\
(0.009)\end{array}$ & $\begin{array}{c}0.041 \\
(0.006)\end{array}$ & $\begin{array}{c}0.093 \\
(0.007)\end{array}$ & $\begin{array}{c}0.081 \\
(0.016)\end{array}$ & $\begin{array}{c}0.063 \\
(0.006)\end{array}$ & $\begin{array}{c}0.028 \\
(0.004)\end{array}$ & $\begin{array}{c}0.024 \\
(0.581)\end{array}$ & $\begin{array}{c}0.015 \\
(2.268)\end{array}$ & $\begin{array}{c}0.016 \\
(0.003)\end{array}$ & $\begin{array}{c}0.055 \\
(0.005)\end{array}$ \\
\hline $\begin{array}{l}\text { Manitoba } \\
\text { Alvar }\end{array}$ & $\begin{array}{l}0.616 \\
-0.05\end{array}$ & $\begin{array}{c}0.268 \\
(0.083)\end{array}$ & $\begin{array}{c}0.240 \\
(0.091)\end{array}$ & $\begin{array}{c}0.161 \\
(0.021)\end{array}$ & NA & $\begin{array}{c}0.000 \\
(0.002)\end{array}$ & $\begin{array}{c}0.147 \\
(0.025)\end{array}$ & NA & $\begin{array}{c}0.049 \\
(4.048)\end{array}$ & $\begin{array}{c}0.100 \\
(0.023)\end{array}$ & $\begin{array}{c}0.001 \\
(0.002)\end{array}$ \\
\hline Prairie & $\begin{array}{c}0.397 \\
(0.038)\end{array}$ & $\begin{array}{l}0.000 \\
\text { (NA) }\end{array}$ & $\begin{array}{l}0 \\
0\end{array}$ & $\begin{array}{c}0.002 \\
(0.002)\end{array}$ & NA & $\begin{array}{c}0.029 \\
(0.008)\end{array}$ & $\begin{array}{c}0.000 \\
(0.000)\end{array}$ & NA & $\begin{array}{c}0.027 \\
(0.008)\end{array}$ & $\begin{array}{c}0.006 \\
(0.004)\end{array}$ & $\begin{array}{c}0.028 \\
(0.008)\end{array}$ \\
\hline Region & Emergence & $\begin{array}{c}2016 \\
\text { Flower } \\
\text { Number }\end{array}$ & $\begin{array}{c}2017 \\
\text { Flower } \\
\text { Number }\end{array}$ & $\begin{array}{c}2018 \\
\text { Flower } \\
\text { Number }\end{array}$ & $\begin{array}{c}2016 \\
\text { Fruit } \\
\text { Number }\end{array}$ & $\begin{array}{c}2017 \\
\text { Fruit } \\
\text { Number }\end{array}$ & $\begin{array}{c}2018 \\
\text { Fruit } \\
\text { Number }\end{array}$ & $\begin{array}{l}\text { Seed } \\
\text { Mass } \\
2016\end{array}$ & $\begin{array}{c}\text { Seed } \\
\text { Mass } \\
2017\end{array}$ & $\begin{array}{l}\text { Seed } \\
\text { Mass } \\
2018\end{array}$ & $\begin{array}{c}\text { Cumulative } \\
\text { Seed Mass } \\
\text { to } 2017\end{array}$ \\
\hline $\begin{array}{l}\text { Great Lakes } \\
\text { Alvar }\end{array}$ & 1.517 & 0.034 & 0.014 & 0.053 & 0.099 & 0.029 & 0.028 & 0.246 & 0.106 & 0 & 0 \\
\hline $\begin{array}{l}\text { Manitoba } \\
\text { Alvar }\end{array}$ & 1.616 & 0.122 & 0.115 & 0.126 & NA & 0.006 & 0.113 & NA & 0.235 & 0.001 & 0 \\
\hline Prairie & 1.522 & 0 & 0 & 0.011 & NA & 0.038 & 0 & NA & 0.001 & 0 & 0.001 \\
\hline
\end{tabular}


Table 3. (A) Narrow-sense heritability and standard error and (B) evolvability (coefficient of additive genetic variation) of Geum triflorum phenology events grown in a common garden.

\begin{tabular}{|c|c|c|c|c|c|c|c|c|}
\hline Region & $\begin{array}{l}\text { Number of } \\
\text { Days to } \\
\text { Emergence }\end{array}$ & $\begin{array}{l}\text { Planting } \\
\text { to First } \\
\text { Flower } \\
2016\end{array}$ & $\begin{array}{l}\text { Planting } \\
\text { to First } \\
\text { Flower } \\
2017\end{array}$ & $\begin{array}{c}\text { Planting } \\
\text { to First } \\
\text { Flower } \\
2018\end{array}$ & $\begin{array}{l}\text { Planting } \\
\text { to Fruit } \\
2017\end{array}$ & $\begin{array}{l}\text { Planting } \\
\text { to Fruit } \\
2018\end{array}$ & $\begin{array}{l}\text { Planting } \\
\text { to Bolt } \\
2017\end{array}$ & $\begin{array}{c}\text { Planting } \\
\text { to Bolt } \\
2018\end{array}$ \\
\hline $\begin{array}{l}\text { Great Lakes } \\
\text { Alvar }\end{array}$ & $\begin{array}{c}0.257 \\
(0.021)\end{array}$ & $\begin{array}{c}0.002 \\
(0.001)\end{array}$ & $\begin{array}{c}0.202 \\
(0.003)\end{array}$ & $\begin{array}{c}0.197 \\
(0.057)\end{array}$ & $\begin{array}{c}0.000 \\
(0.000)\end{array}$ & $\begin{array}{c}0.059 \\
(0.018)\end{array}$ & $\begin{array}{c}0.059 \\
(0.045)\end{array}$ & $\begin{array}{c}0.011 \\
(0.012)\end{array}$ \\
\hline $\begin{array}{l}\text { Manitoba } \\
\text { Alvar }\end{array}$ & $\begin{array}{c}0.154 \\
(0.070)\end{array}$ & $\begin{array}{c}0.000 \\
(0.000)\end{array}$ & $\begin{array}{c}0.136 \\
(0.054)\end{array}$ & $\begin{array}{c}0.086 \\
(0.130)\end{array}$ & $\begin{array}{c}0.010 \\
(0.042)\end{array}$ & $\begin{array}{c}0.013 \\
(0.026)\end{array}$ & $\begin{array}{c}0.001 \\
(0.015)\end{array}$ & $\begin{array}{c}0.013 \\
(0.037)\end{array}$ \\
\hline Prairie & $\begin{array}{c}0.026 \\
(0.016) \\
\end{array}$ & $\begin{array}{c}0.000 \\
(0.000) \\
\end{array}$ & $\begin{array}{c}0.000 \\
(0.000) \\
\end{array}$ & $\begin{array}{c}0.000 \\
(0.000)\end{array}$ & $\begin{array}{c}0.000 \\
(0.000)\end{array}$ & $\begin{array}{c}0.013 \\
(0.021) \\
\end{array}$ & $\begin{array}{c}0.001 \\
(0.012) \\
\end{array}$ & $\begin{array}{c}0.001 \\
(0.008) \\
\end{array}$ \\
\hline \\
\hline Region & $\begin{array}{l}\text { Number of } \\
\text { Days to } \\
\text { Emergence }\end{array}$ & $\begin{array}{l}\text { Planting } \\
\text { to First } \\
\text { Flower } \\
2016\end{array}$ & $\begin{array}{c}\text { Planting } \\
\text { to First } \\
\text { Flower } \\
2017\end{array}$ & $\begin{array}{c}\text { Planting } \\
\text { to First } \\
\text { Flower } \\
2018\end{array}$ & $\begin{array}{c}\text { Planting } \\
\text { to Fruit } \\
2017\end{array}$ & $\begin{array}{l}\text { Planting } \\
\text { to Fruit } \\
2018\end{array}$ & $\begin{array}{l}\text { Planting } \\
\text { to Bolt } \\
2017\end{array}$ & $\begin{array}{c}\text { Planting } \\
\text { to Bolt } \\
2018\end{array}$ \\
\hline $\begin{array}{l}\text { Great Lakes } \\
\text { Alvar }\end{array}$ & 0.111 & 0 & 0 & 0.003 & 0 & 0.001 & 0.004 & 0.001 \\
\hline $\begin{array}{l}\text { Manitoba } \\
\text { Alvar }\end{array}$ & 0.147 & 0 & 0.002 & 0.003 & 0.001 & 0.001 & 0.001 & 0.001 \\
\hline Prairie & 0.049 & 0 & 0 & 0 & 0 & 0.001 & 0 & 0.001 \\
\hline
\end{tabular}




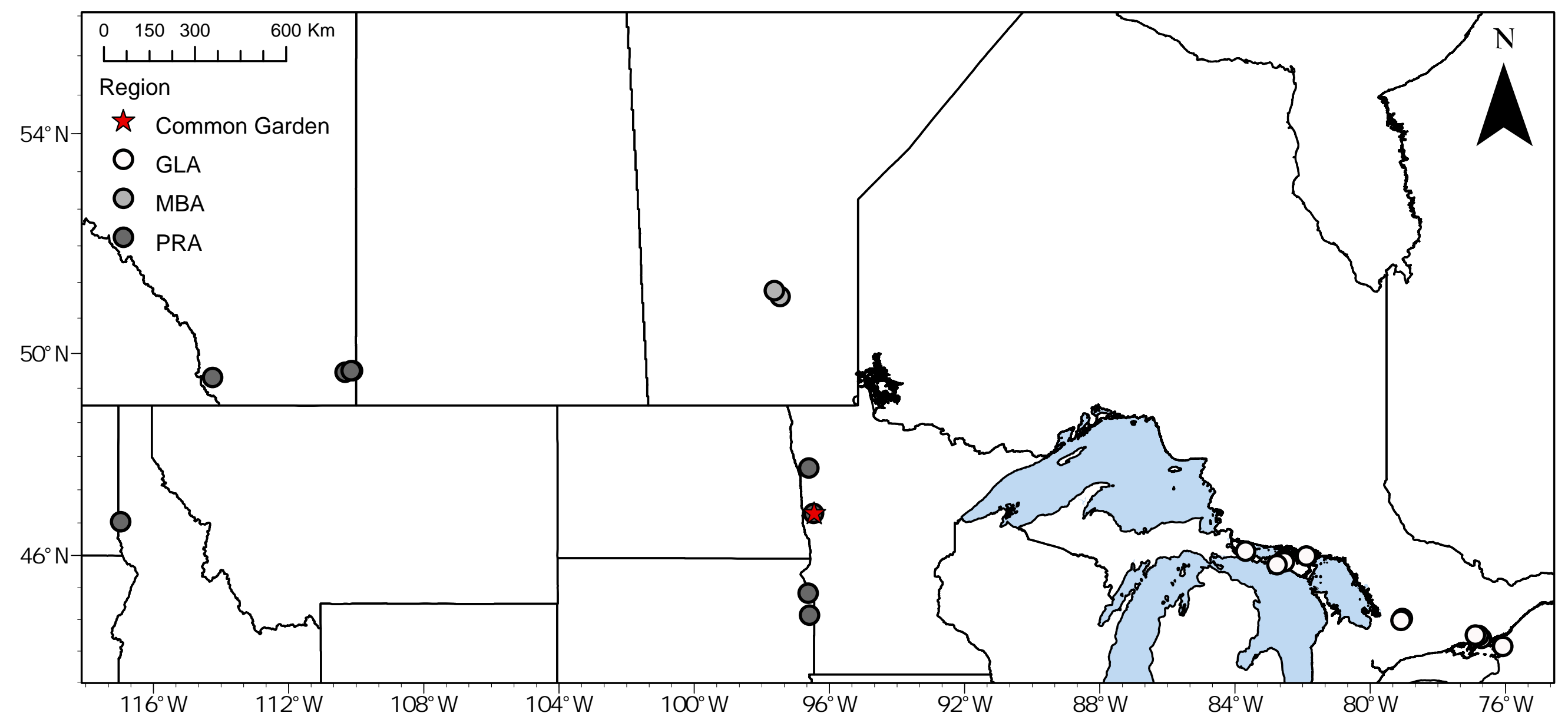




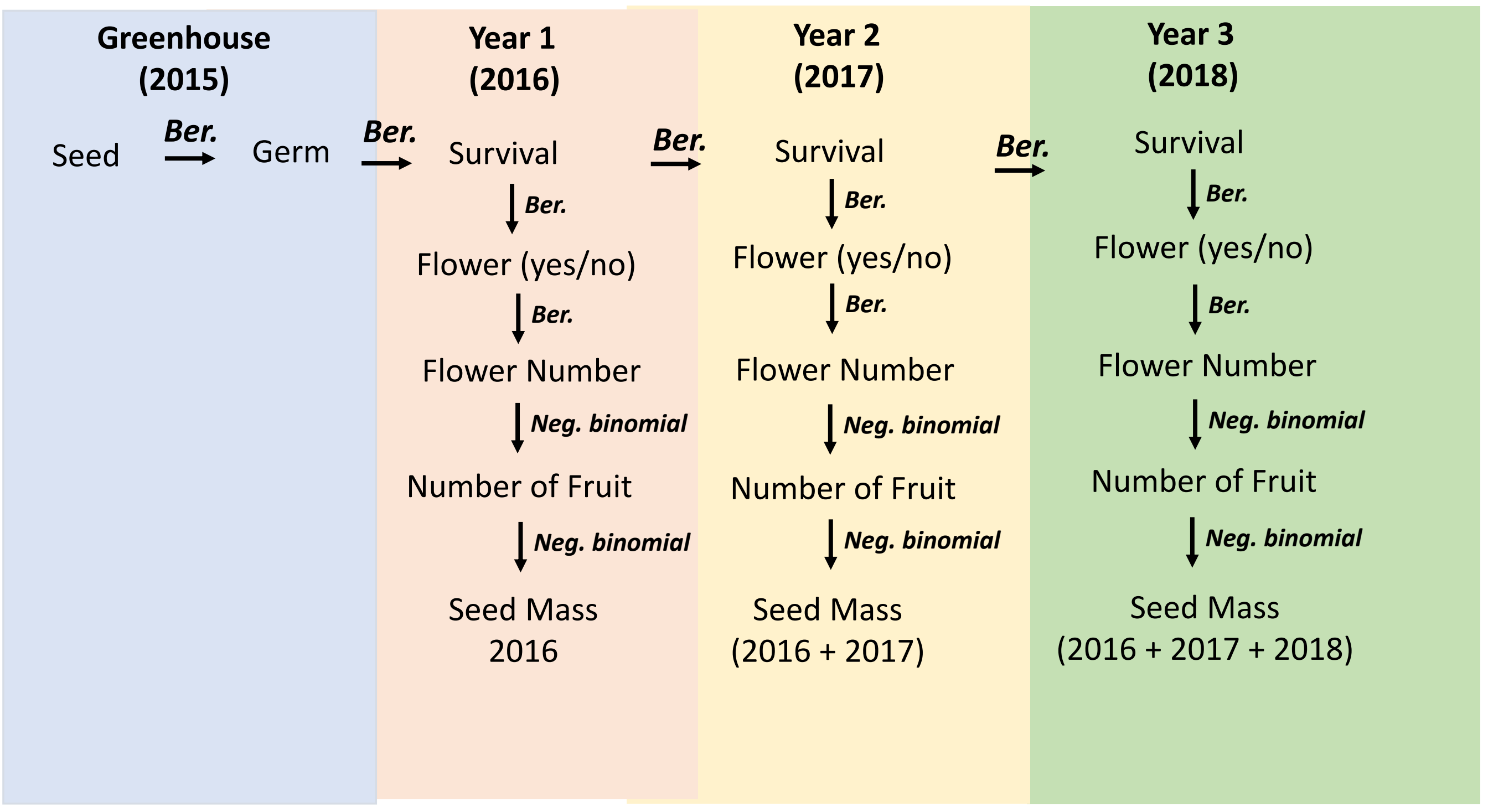


1250 - bioRxiv preprint doi: https://doi.org/10.1101/2021.10.12.464067; this version posted October 14,2021 . The copyright holder for this preprint (which was not certified by peer review) is the author/funder, who has granted bioRxiv a license to display the preprint in perpetuity. It is made available under aCC-BY 4.0 International license.

\section{$\bigcirc$ GLA \\ $\square$ MBA \\ $\triangle$ PRA}

1000 -

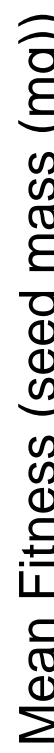


$\square$ Great Lake Alvar $\square$ Manitoba Alvar

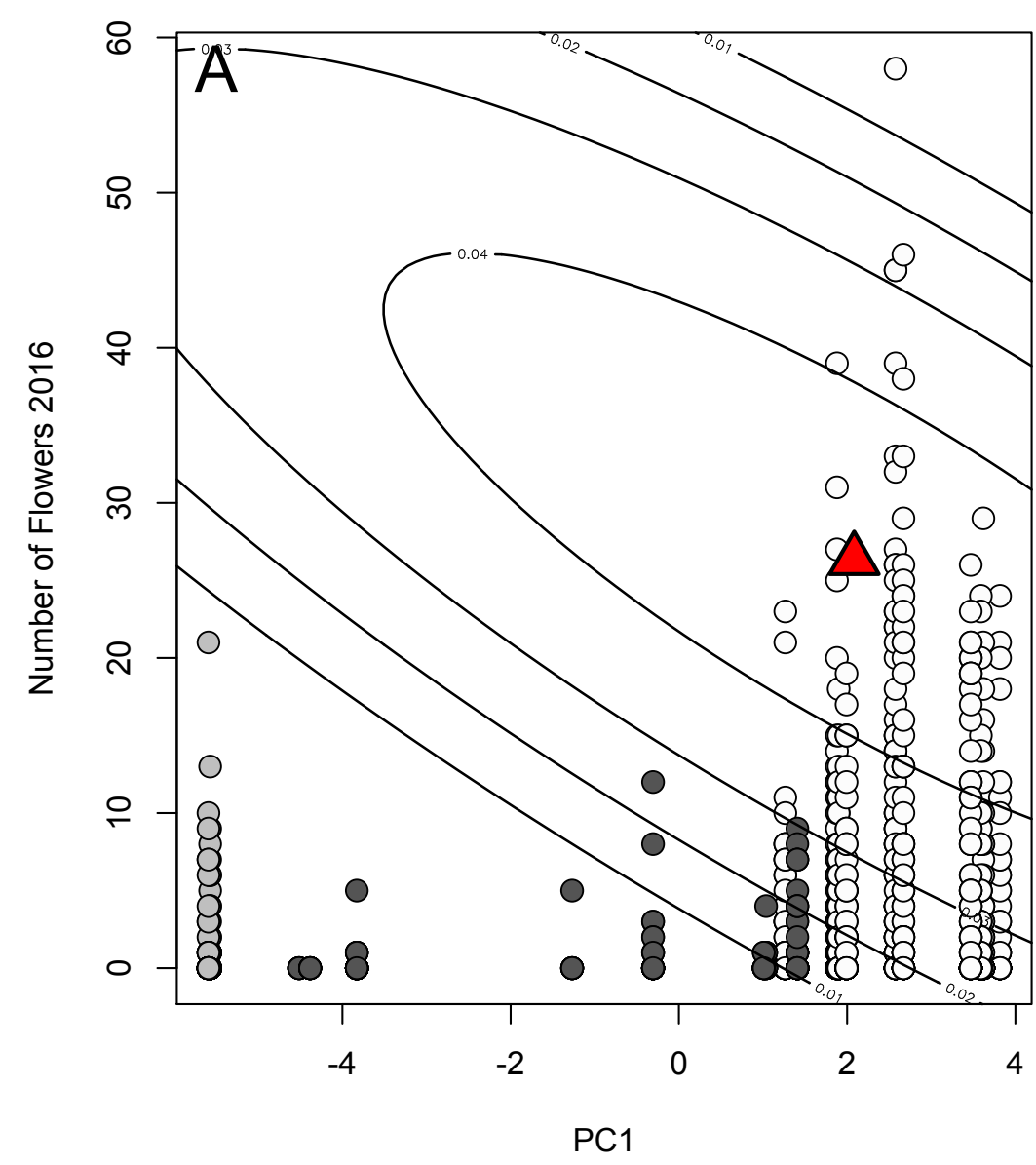

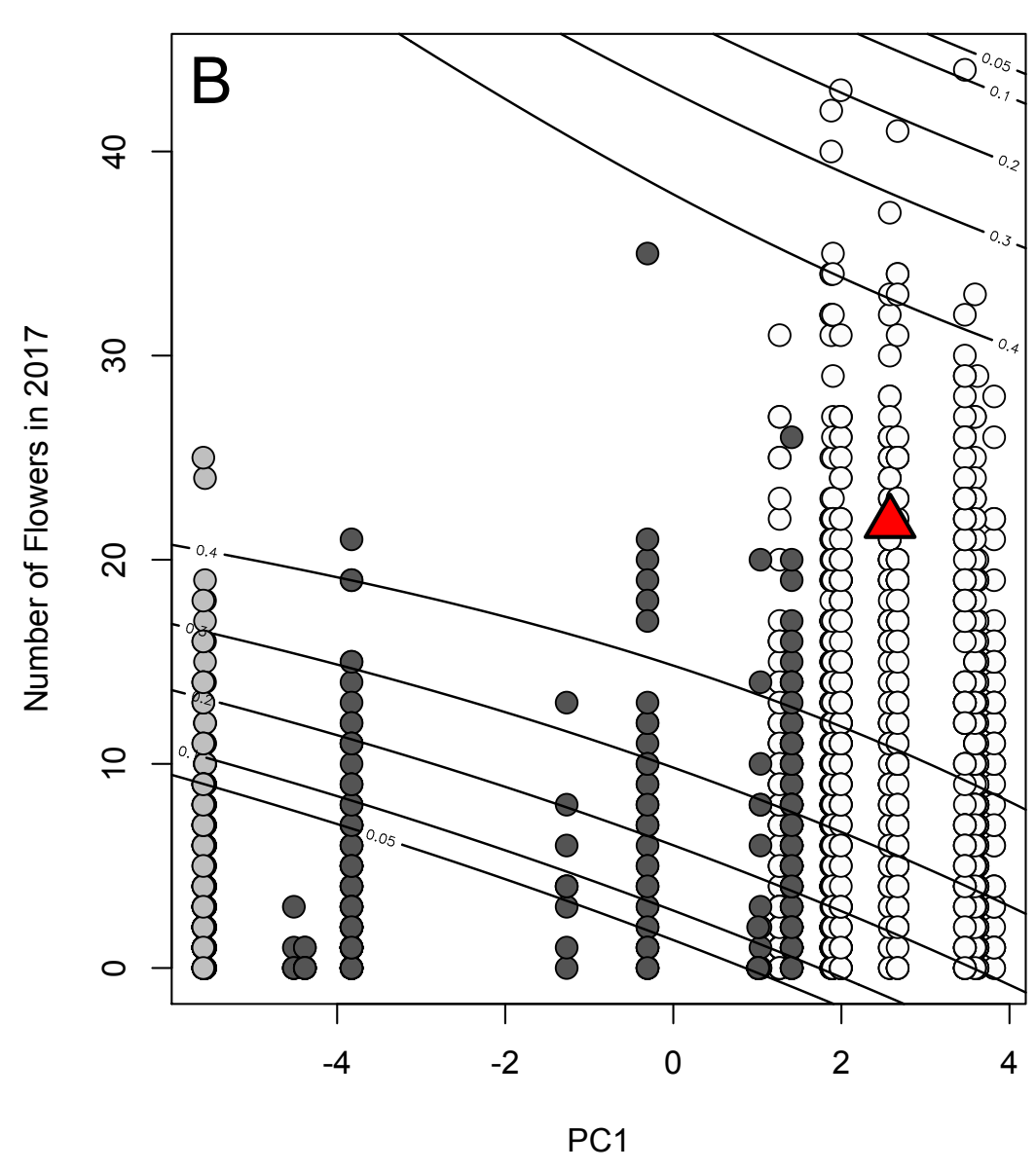

Prairie

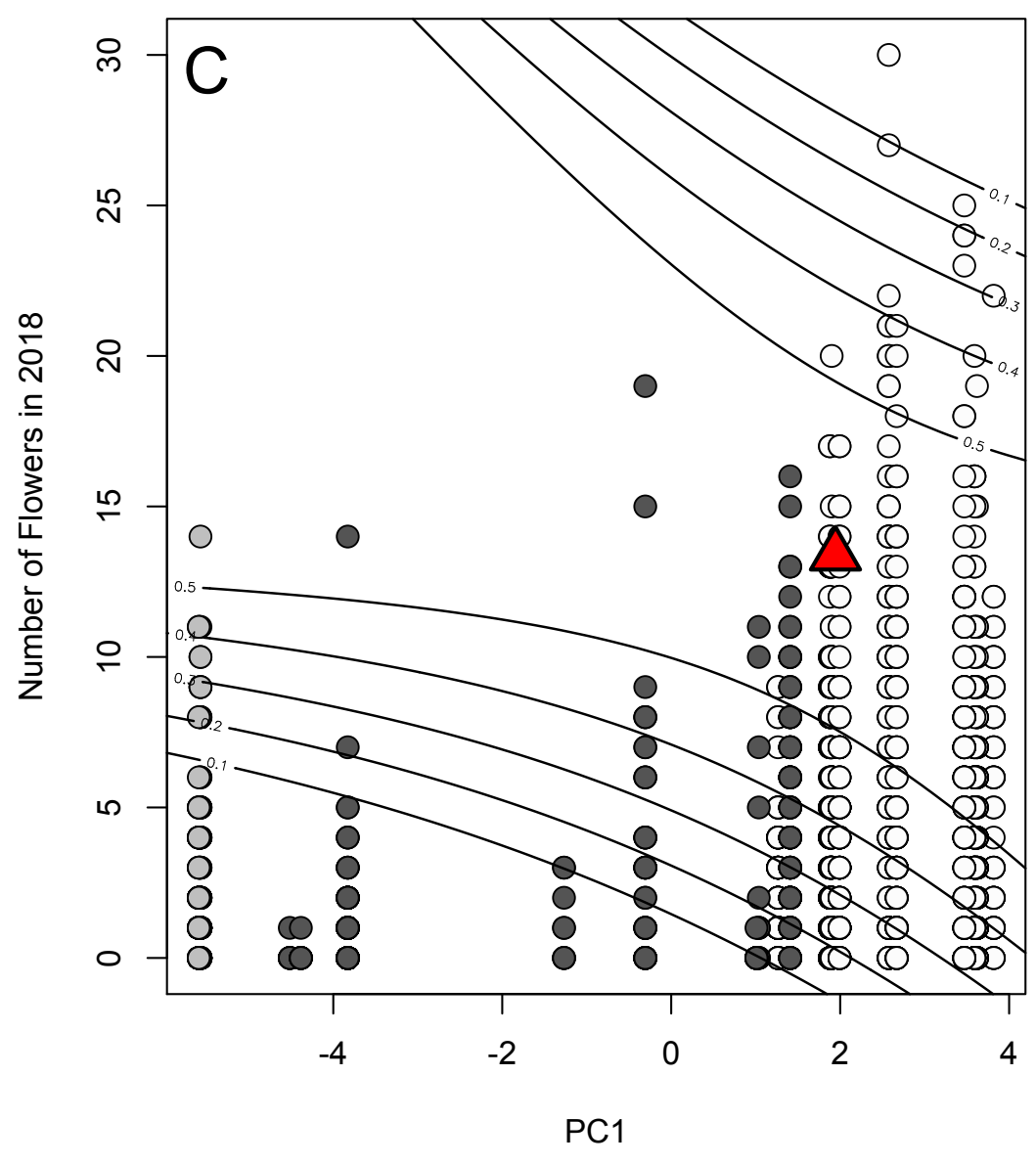


Table 2. (A) Narrow-sense heritability and standard error and (B) evolvability (coefficient of additive genetic variation) of Geum triflorum fitness expressions grown in a common garden environment.

A

\begin{tabular}{|c|c|c|c|c|c|c|c|c|c|c|c|c|}
\hline Region & Emergence & $\begin{array}{c}2016 \\
\text { Flower } \\
\text { Number }\end{array}$ & $\begin{array}{c}2017 \\
\text { Flower } \\
\text { Number }\end{array}$ & $\begin{array}{c}2018 \\
\text { Flower } \\
\text { Number }\end{array}$ & $\begin{array}{c}2016 \\
\text { Fruit } \\
\text { Number }\end{array}$ & $\begin{array}{c}2017 \\
\text { Fruit } \\
\text { Number }\end{array}$ & $\begin{array}{c}2018 \\
\text { Fruit } \\
\text { Number }\end{array}$ & $\begin{array}{c}\text { Seed } \\
\text { Mass } \\
2016\end{array}$ & $\begin{array}{c}\text { Seed } \\
\text { Mass } \\
2017\end{array}$ & $\begin{array}{c}\text { Seed } \\
\text { Mass } \\
2018\end{array}$ & $\begin{array}{c}\text { Cumulative } \\
\text { Seed Mass } \\
\text { to } 2017\end{array}$ & $\begin{array}{c}\text { Cumulative } \\
\text { Seed Mass } \\
\text { to } 2018\end{array}$ \\
\hline $\begin{array}{c}\text { Great Lakes } \\
\text { Alvar }\end{array}$ & $\begin{array}{c}0.644 \\
(0.020)\end{array}$ & $\begin{array}{c}0.196 \\
(0.009)\end{array}$ & $\begin{array}{c}0.041 \\
(0.006)\end{array}$ & $\begin{array}{c}0.093 \\
(0.007)\end{array}$ & $\begin{array}{c}0.081 \\
(0.016)\end{array}$ & $\begin{array}{c}0.063 \\
(0.006)\end{array}$ & $\begin{array}{c}0.028 \\
(0.004)\end{array}$ & $\begin{array}{c}0.024 \\
(0.581)\end{array}$ & $\begin{array}{c}0.015 \\
(2.268)\end{array}$ & $\begin{array}{c}0.016 \\
(0.003)\end{array}$ & $\begin{array}{c}0.055 \\
(0.005)\end{array}$ & $\begin{array}{c}0.126 \\
(0.008)\end{array}$ \\
\hline $\begin{array}{c}\text { Manitoba } \\
\text { Alvar }\end{array}$ & $\begin{array}{c}0.616 \\
(0.050)\end{array}$ & $\begin{array}{c}0.268 \\
(0.083)\end{array}$ & $\begin{array}{c}0.240 \\
(0.091)\end{array}$ & $\begin{array}{c}0.161 \\
(0.021)\end{array}$ & $\begin{array}{c}\text { NA } \\
(\mathrm{NA})\end{array}$ & $\begin{array}{c}0.000 \\
(0.002)\end{array}$ & $\begin{array}{c}0.147 \\
(0.025)\end{array}$ & $\begin{array}{c}\text { NA } \\
(\mathrm{NA})\end{array}$ & $\begin{array}{c}0.049 \\
(4.048)\end{array}$ & $\begin{array}{c}0.100 \\
(0.023)\end{array}$ & $\begin{array}{c}0.001 \\
(0.002)\end{array}$ & $\begin{array}{c}0.040 \\
(0.012)\end{array}$ \\
\hline Prairie & $\begin{array}{c}0.397 \\
(0.038)\end{array}$ & $\begin{array}{c}0.000 \\
(\mathrm{NA})\end{array}$ & $\begin{array}{c}0.000 \\
(0)\end{array}$ & $\begin{array}{c}0.002 \\
(0.002)\end{array}$ & $\begin{array}{c}\text { NA } \\
(\mathrm{NA})\end{array}$ & $\begin{array}{c}0.029 \\
(0.008)\end{array}$ & $\begin{array}{c}0.000 \\
(0.000)\end{array}$ & $\begin{array}{c}\text { NA } \\
(\mathrm{NA})\end{array}$ & $\begin{array}{c}0.027 \\
(0.008)\end{array}$ & $\begin{array}{c}0.006 \\
(0.004)\end{array}$ & $\begin{array}{c}0.028 \\
(0.008)\end{array}$ & $\begin{array}{c}0.001 \\
(0.002)\end{array}$ \\
\hline
\end{tabular}

B

\begin{tabular}{|c|c|c|c|c|c|c|c|c|c|c|c|c|}
\hline Region & Emergence & $\begin{array}{c}2016 \\
\text { Flower } \\
\text { Number }\end{array}$ & $\begin{array}{c}2017 \\
\text { Flower } \\
\text { Number }\end{array}$ & $\begin{array}{c}2018 \\
\text { Flower } \\
\text { Number }\end{array}$ & $\begin{array}{c}2016 \\
\text { Fruit } \\
\text { Number }\end{array}$ & $\begin{array}{c}2017 \\
\text { Fruit } \\
\text { Number }\end{array}$ & $\begin{array}{c}2018 \\
\text { Fruit } \\
\text { Number }\end{array}$ & $\begin{array}{c}\text { Seed } \\
\text { Mass } \\
2016\end{array}$ & $\begin{array}{l}\text { Seed } \\
\text { Mass } \\
2017\end{array}$ & $\begin{array}{l}\text { Seed } \\
\text { Mass } \\
2018\end{array}$ & $\begin{array}{c}\text { Cumulative } \\
\text { Seed Mass } \\
\text { to } 2017\end{array}$ & $\begin{array}{c}\text { Cumulative } \\
\text { Seed Mass } \\
\text { to } 2018\end{array}$ \\
\hline $\begin{array}{c}\text { Great Lakes } \\
\text { Alvar }\end{array}$ & 1.517 & 0.034 & 0.014 & 0.053 & 0.099 & 0.029 & 0.028 & 0.246 & 0.106 & 0.000 & 0.000 & 0.000 \\
\hline $\begin{array}{l}\text { Manitoba } \\
\text { Alvar }\end{array}$ & 1.616 & 0.122 & 0.115 & 0.126 & NA & 0.006 & 0.113 & NA & 0.235 & 0.001 & 0.000 & 0.000 \\
\hline Prairie & 1.522 & 0.000 & 0.000 & 0.011 & NA & 0.038 & 0.000 & NA & 0.001 & 0.000 & 0.001 & 0.000 \\
\hline
\end{tabular}

